\title{
Modernization of telecommunication networks on the basis of studying demographic processes using GIS
}

\author{
Sharafatdin Narbaev ${ }^{1}$, Sarvar Abdurahmanov ${ }^{1 *}$, Olimjon Allanazarov ${ }^{2}$ Albina Talgatovna ${ }^{2}$ \\ and Ilhomjon Aslanov ${ }^{1}$
}

\begin{abstract}
${ }^{1}$ Tashkent Institute of Irrigation and Agricultural Mechanization Engineers, 39 Qori Niyozi Str., 100000, Tashkent, Uzbekistan

${ }^{2}$ Tashkent state technical university named by Islam Karimov. 2 Universitet str. 100095 Tashkent Uzbekistan.
\end{abstract}

\begin{abstract}
The article studies and analyzes the geographical position of households, educational institutions, enterprises and organizations in settlements of the southern region of the Republic of Uzbekistan and their exact number in order to provide the population with telecommunication networks and Internet systems in the republic, as well as to improve the efficiency of fiber-optic cables. We have developed a special methodology for the analysis and study of demographic processes, consisting of six stages, based on cartographic methods. On their basis, a large-scale digital electronic sitemap was created using data from the State Statistics Committee.
\end{abstract}

\section{Introduction}

The development of modern methods of mapping that characterize the demographic processes in the world, the creation, visualization, and integration of interactive dynamic maps based on geographic information systems and technologies are of great importance. In particular, the study of the impact of local demographic processes in the dynamics of urbanization is one of the most important issues in the field of cartography. In this regard, special attention is paid to the study of all situations related to the population, including the population of the USA, China, Germany, South Korea, Russia, and other economically developed countries, as well as the creation of population maps and their reliability.

Currently, the main tasks of our country are to implement comprehensive measures to improve computer and information technologies, telecommunications networks, data transmission, and Internet services, including the construction of new telecommunications facilities, the use of modern technologies to improve the existing infrastructure. Thus, these studies correspond to the tasks set out in the regulatory documents related to the activities

*Corresponding author: s.n.abduraxmonov@gmail.com, s.abduraxmonov@tiiame.uz 
of the industry, in order to ensure the implementation of Decree No.UP-5349 of February 19, 2018 "On measures to further improve information technology and communications" [1].

The aim of the work is to study the demographic processes of the southern region of the Republic of Uzbekistan based on geoinformation technologies and cartographic methods, create and map geolocation databases, model and integrating spatial data, improving the visualization of processes, and creating a series of maps using the above methods to provide the population with high-quality networks and Internet systems in the republic, as well as for the optimization of fiber-optic cables.

\section{Methods and material}

Cartographic, aerospace, statistical, GIS technologies - ArcGIS, QGIS, Mapinfo, GIS Panorama, PhotoMOD and others, questionnaires, regional analysis, geolocation methods.

\subsection{Theory/computation}

Geographic information systems technologies are used in various fields, including all cadastral work in the State Committee for Land Resources, Geodesy, Cartography and Cadastre of the Republic of Uzbekistan: architectural design, three-dimensional modeling of buildings, remote astronomical observations, remote design and engineering design, work, etc.

Technologies "Geoinformation systems" are used not only in the state cadastral research, but also in the creation of digital maps and databases, and in general, in carrying out numerous studies on the creation of "Geoinformation systems" in each area.

Currently, there are many software tools for the use and creation of "Geographic Information Systems" in all areas. When choosing software products for developing an organization's long-term plan, the following factors should be taken into account:

- the popularity and availability of the program;

- practical experience in similar projects;

- ease of installation and use;

- the need to take into account the possibility of exporting other data to GIS programs.

To provide the population with high-quality networks and Internet systems in the republic, as well as to optimize fiber-optic cables, it is necessary to study the geographic position of the existing location and analyze the exact number of households, educational institutions, enterprises and organizations in settlements.

To implement the above ideas, it was necessary to create a large-scale digital electronic sitemap using data from Goskomstat. Purposeful systematic research to define the digital mapping methodology showed that this methodology is fundamentally different from the flowchart used to create large-scale maps, and has developed a system consisting of five stages (Figure 1).

At the first stage, large-scale topographic maps at a scale of 1: 10,000 for the regions under study and a collection of digital images from unmanned aerial vehicles (UAVs) are collected, as well as the collection of text and tabular data on telecommunications $[2,3]$.

In the second phase, topographic maps at a scale of 1: 10,000 will be scanned, and topographic images in Adobe Photoshop will be prepared for geographic information systems. Digital images (remote sensing images) will be linked to the compiled topobases and saved in the computer memory using Adobe Photoshop. Text collections of telecommunication resources will be systematized and stored in the computer memory in Microsoft Word. Specific task tables are also organized and loaded into computer memory based on Microsoft Excel. 
At the third stage, the topographic materials prepared for Geographic Information Systems in Adobe Photoshop are processed in Mapinfo and ArcGIS. Digital remote sensing images are descriptive using GIS Panorama and PhotoMOD software and are associated with topographic data. The texts collected on this topic are replenished on the basis of processed topographic images and digital images (remote sensing materials), as well as newly revealed materials. The filled-in text information is systematically converted into computer memory as a new option based on Microsoft Excel.

The final stage, which is to create a digital map of the main issue of advanced telecommunications to create a database based on the theme of digital maps (Figure 1).

When designing key elements of a map, it is often assumed that it contains information about the map itself. One of the main goals of the work is to provide users with a clear and understandable map for creating planned work.

Thus, telecommunication cards are a component of communication cards, which include an updated system of information and documentation about geographic location, legal status, quantity, quality data and value of a particular type of business or other object. Using the given technological scheme, symbols and general geographic elements of maps were developed in accordance with the requirements of government services and taking into account the capabilities of map users.

When laying fiber-optic cables, special attention should be paid to demographic processes, which were originally associated with the population in villages. A special place is occupied by the implementation of such demographic and economic reforms.

As a result of the study, a special methodology for the analysis of demographic processes was developed, consisting of the following stages, which do not differ from the methods used to study demographic processes based on cartographic methods [4].

This methodology was developed for mapping fiber-optic cables in the Mirishkor region of the southern demographic region (Kashkadarya region) for the purpose of mapping demographic processes. The methodological foundations of the study and study of demographic processes in the region are based on the methods of cartographic research. By analyzing regional demographic data using mapping techniques, the problem can be clearly identified. 


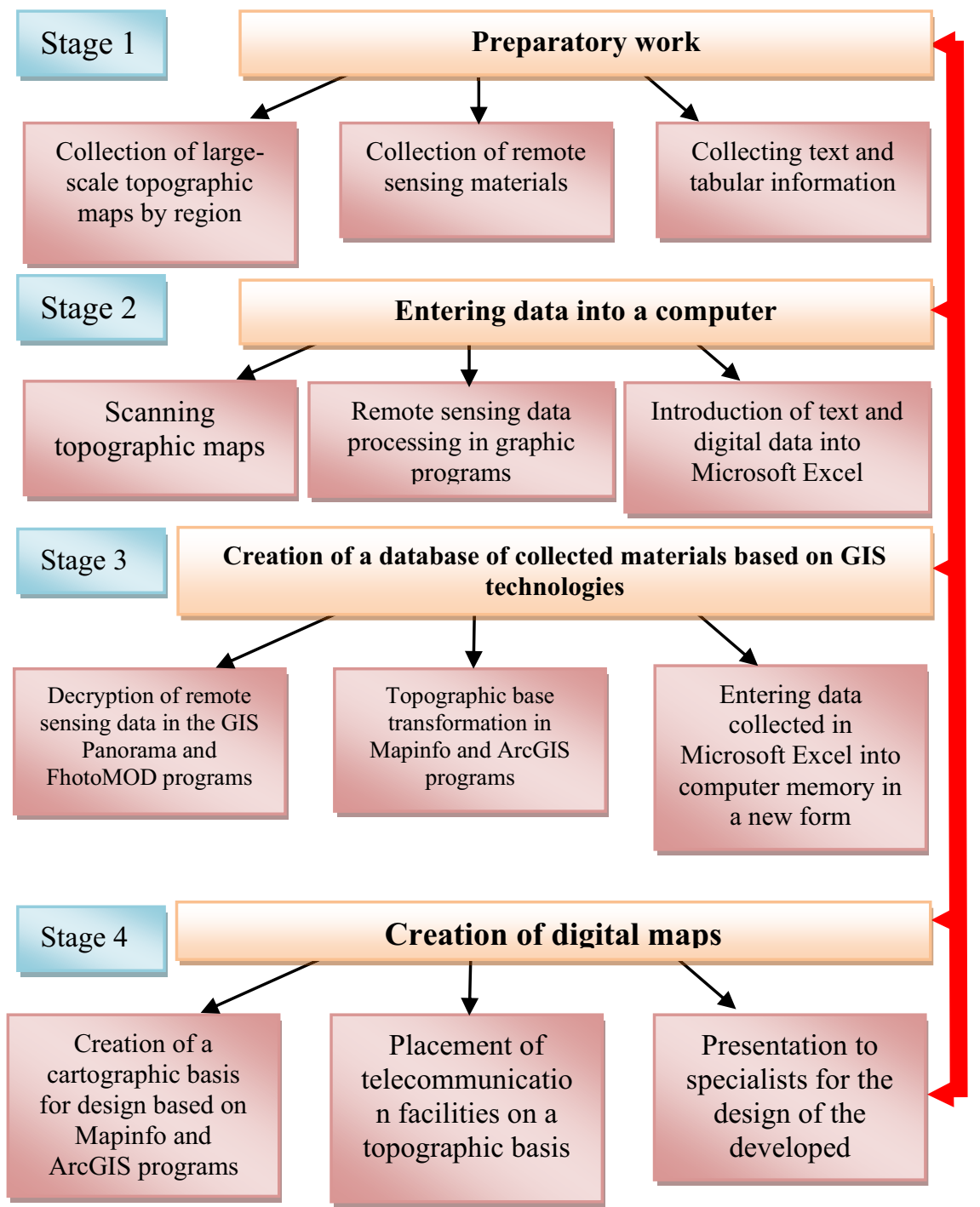

Fig. 2. Methodology of analysis of demographic processes 
Specific demographic characteristics of the region were determined on the basis of population maps. Maps account for changes in population, density, number of farms, school and preschool education centers, and government agencies.

When developing a demographic map, statistical information is obtained from the relevant industry organizations, depending on the theme of the map being designed. All segments of the population play an enormous role, as these maps will serve the development of other areas and the creation of local programs. When compiling maps, cartographic and graphic materials, including sections, diagrams, tables, figures, text, remote sensing materials are used as the main sources.

When creating population maps, first of all, reliable data are collected and their database is created, and on the basis of these data it is necessary to develop an electronic digital cartographic database of the region (Figure 3).

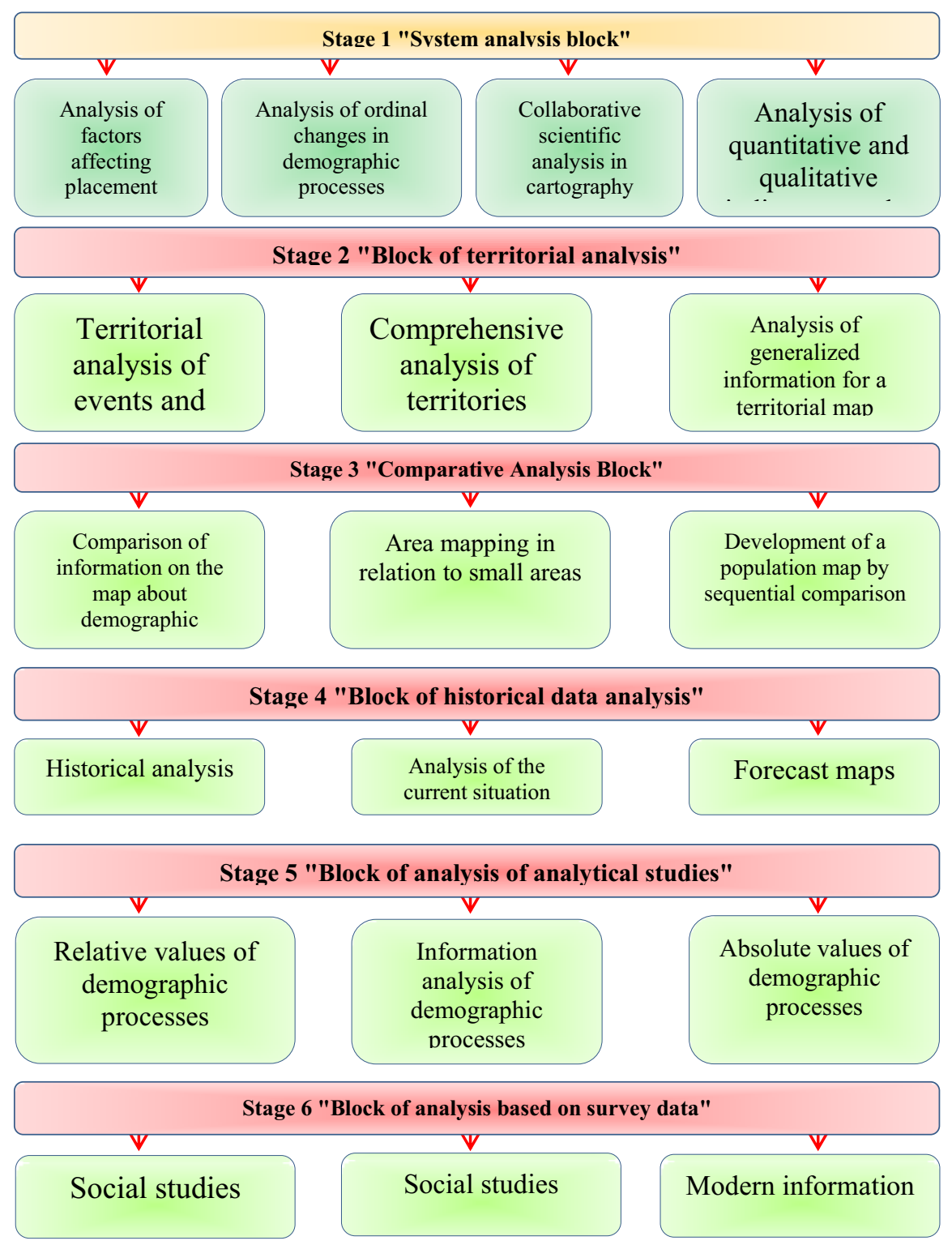




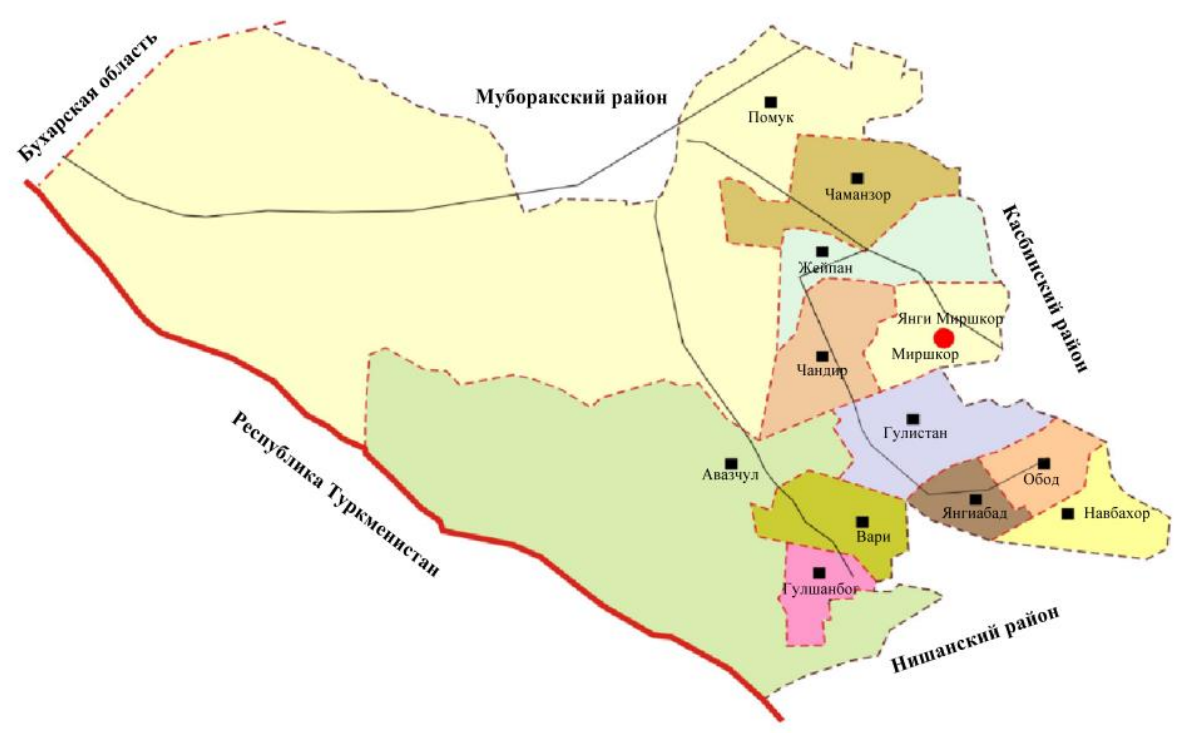

Fig. 3. Map of the rural district of Mirishkor district

\section{Results}

Thus, as a result of targeted studies of demographic processes in the southern region using GIS technology in mapping in different directions, it became necessary to quickly collect data and create databases using new cost-effective methods.

As an example, there is a database where the average number of households was 5-6 people per family. As a result, the total capacity of the cables was determined, which was calculated by connecting to government bodies (table 1).

Table 1. Information about the population in Mirishkor region

\begin{tabular}{|c|l|c|c|c|}
\hline № & \multicolumn{1}{|c|}{ Village name } & Population 2019 & Population 2018 & Difference \\
\hline 1 & Mirishkor & 3121 & 3058 & 63 \\
\hline 2 & Yangi Mirishkor & 3798 & 3791 & 7 \\
\hline 3 & Okmachit & 1938 & 1894 & 44 \\
\hline 4 & Uzbekiston & 2546 & 2496 & 50 \\
\hline 5 & Obodon & 3780 & 3780 & 0 \\
\hline 6 & Kumbangi & 2780 & 2773 & 7 \\
\hline 7 & Kalta & 3796 & 3743 & 53 \\
\hline 8 & Yangi Zheinov & 4980 & 4800 & 180 \\
\hline 9 & Avvona & 3624 & 4186 & -562 \\
\hline 10 & Kattapoy & 3901 & 3841 & 60 \\
\hline 11 & Yangi arik & 5710 & 7273 & -1563 \\
\hline 12 & Isabod & 49715 & 4931 & 40 \\
\hline 13 & Oltin bosho & 2210 & 2200 & 10 \\
\hline 14 & Chamanzor & 4450 & 4400 & 50 \\
\hline 15 & Shirin & 38655 & 3655 & 210 \\
\hline 16 & Guliston & 2320 & 2320 & 0 \\
\hline 17 & Pomuk & 2975 & 2975 & 0 \\
\hline 18 & Bahoriston & 2338 & 2338 & 0 \\
\hline
\end{tabular}




\begin{tabular}{|c|c|c|c|c|}
\hline 19 & Ignachi & 3375 & 3375 & 0 \\
\hline 20 & Malla & 2360 & 2370 & -10 \\
\hline 21 & Yangi kishlok & 2880 & 2855 & 25 \\
\hline 22 & Gulobod & 2700 & 2680 & 20 \\
\hline 23 & Chandir & 1802 & 2235 & -433 \\
\hline 24 & Madaniyat & 3021 & 3121 & -100 \\
\hline 25 & Yangi hayot & 3650 & 3815 & -165 \\
\hline 26 & Istiklol & 4460 & 4460 & 0 \\
\hline 27 & Shodlik & 1840 & 1795 & 45 \\
\hline 28 & Zafar & 2780 & 2730 & 50 \\
\hline 29 & Guliston & 4610 & 4583 & 27 \\
\hline 30 & Rim & 4281 & 4200 & 81 \\
\hline 31 & Navbahor & 4384 & 4340 & 44 \\
\hline 32 & Yangiobod & 1150 & 1295 & -145 \\
\hline 33 & Buston & 1930 & 1920 & 10 \\
\hline 34 & Bori & 2083 & 2184 & -101 \\
\hline 35 & Gulshanbog & 2415 & 2350 & 65 \\
\hline & Total & 112824 & 114762 & -1938 \\
\hline
\end{tabular}

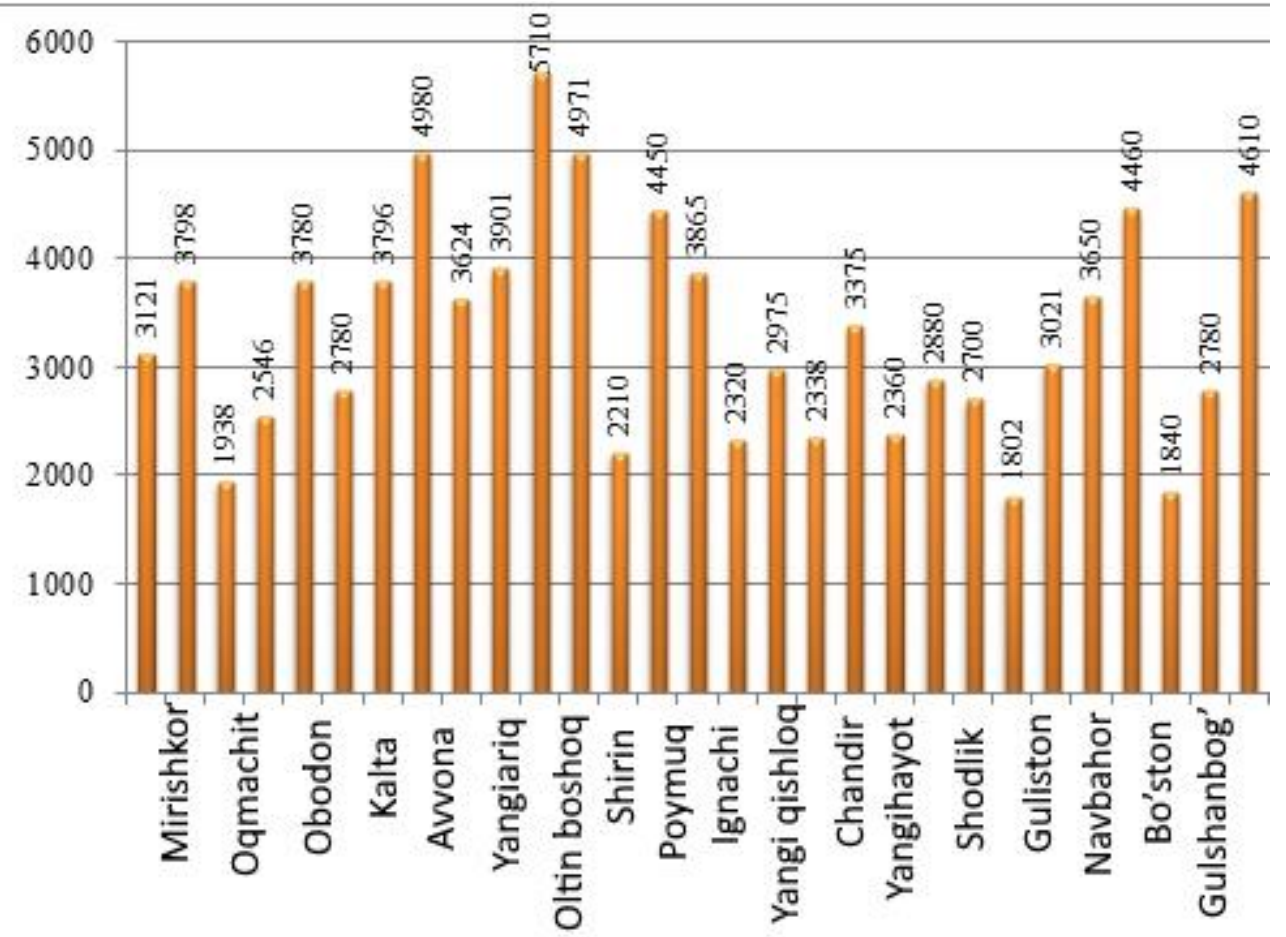

Fig. 4. Shows a diagram of the population size, taking into account which the need for a particular settlement for cable laying can be identified.

The highest population is observed in the village of Yangi Arik (5710), and the lowest is 1150 in the village of Yangiabad. It follows from the diagram that for each family of 5-6 people in the village of Yangi arik $(5710: 5.5=1038.18)$, on average, 1040 households 
need to be organized, in the village of Yangiabad $(1150: 5.5=209)$ the average number of households is 210 . As a result of this analysis will be carried out design work.

In addition, cards allow cables to be routed along the shortest and least expensive routes. For example, if you need to mark the route from the district center to the village, where the necessary directions are indicated.

\section{Conclusions}

The work considered the work on the creation of maps and plans, their processing, and data integration in GIS technologies. GIS-based demographic maps have become an indispensable tool for a number of practical tasks and research related to population. Creation of electronic digital maps of the population on computer programs using special methods of cartographic research, provides the speed of analysis, processing, and forecasting of the development of population maps in one system. A special methodology for the analysis of demographic processes was developed, consisting of six stages, based on cartographic methods. Analytical work has been done to quickly identify data based on spatial data modeling using GIS technologies. A structure has been developed for direct data integration into the geoinformation base when compiling digital maps and visualizing demographic processes, as well as conducting automatic analytical work together with updating remote sensing data and based on this analysis of spatial data in all possible ways.

\section{Reference}

1. I.Musaev. A. Mukhtorov. M. Ergashov. Geoinformations systems and technologies. Tashkent 2015.59 p.

2. RV. Gavin, N.G. Markov. Geoinformation systems. Tomsk 2008. It's 69b.

3. Safarov E.No, Prenov Sh.M. and et al. Cartography and geovizualization. Tashkent$2015123 \mathrm{p}$.

4. Huisman O, Ralf A. de By, "Principles of Geographic Information Systems". The Netherlands-2009 year. [453 p.]

5. Popelka S, Brychtoava A,"Olomouc - possibilities of geovisualization of the historicality". Czech Republic-2000 year. [267p.]

6. Jeffrey H, Stuart K. map, James A. Landay, "a toolkit for interactive information visualization". USA-2006 year 2p., 267p.

7. Kang-Tsung dust. Introduction to Geographic Information Systems. Worth edition. McGraw Hill Education (India) 2008. - 450 p.

8. Abdurakhmanov S. N. Development of data on the creation of maps of demographic processes in the system of geographic information technology / / XXI International scientific and practical conference Advances in Science and Technology. Russia in June 2019.

9. Abdurakhmonov S.N. Geoinformatic Systems and Technologies (GAT) and Information on the Use of GPS Accessories in Integrated Demographic Process // International Journal of Multidisciplinary Research and Publications ISSN: 2581-6187. 2019.

10. Akbarova N. Written dissertation for Master's academic degree [10 b.].

11. Raklov V.P., Safarov E.No, it's not., Abdurahimov X.A. Geographic Information Systems. - T.: Science, 2007. - 140 p.

12. Shokirov Sh., I.Musaev. Remote sensing T-2015. 195 p. 
13. Tojiyeva.Z. O`zbekiston aholisi: o`sishi va joydanishi. Monografiya. - T:. Fan texnologiya, 2010.- $113 \mathrm{~b}$

14. Abdurakhmonov S.N., Inamov A.R. Application and integration of innovative technologies in cartographic visualization of regional demographic processes. Tashkent: TIIAME Press, 2018. 107 p. (in Uzbek).

15. Abdurakhmonov S.N. Dadabayeva A., Erkulov G. Development of data on the creation of maps of demographic processes in the system of geographic information technology.XXI International scientific and practical conference "Advances in Science and Technology". Tashkent, June, 2019. P. 50-52. (in Russian).

16. Abdurakhmonov S.N., Inamov A.N. Digitization of state geodetic points and linking objects to these points. Bulletin of the State Committee on Land Resources, Geodesy, Cartography and State Cadastre of the Republic of Uzbekistan. Tashkent, 2013. No 2. 14 p. (in Uzbek).

17. Safarov E.Y., Prenov Sh.M., Allanazarov O.R., Sayidov A.K., Raxmonov D.N. Cartography and geovizualization. Tashkent: TIIAME Press, 2015. 123 p. (in Uzbek).

18. Safarov E.Y., Prenov Sh.M. Design and creation of natural maps. Tashkent: Universitet Press, 2011. 159 p. (in Uzbek).

19. Mirzaliev T., Musaev I., Safarov E.Yu. Socio-economic cartography. Tashkent: Yangi asr avlodi Press, 2009. 165 p. (in Uzbek).

20. Berlyant A.M. Geoinformation mapping. Moscow: Astreya Press, 1997. 198 p. (in Russian).

21. Abdurakhmonov, S., Abdurahmanov, I., Murodova, D., Mirjalolov, N., Djurayev, A.Development of demographic mapping method based on gis technologies. InterCarto, InterGIS, 2020, 26, стр. 319-328. (in English)

22. He Yina, Alexander V. Prishchepovb, Tobias Kuemmerled, Benjamin Bleyhl, Johanna Buchner, Volker C. Radeloff. 2018 Mapping agricultural land abandonment from spatial and temporal segmentation of Landsat time series. https://doi.org/10.1016/j.rse.2018.02.050

23. Jeremy W. Crampton. 2010 Mapping A Critical Introduction to Cartography and GIS. 50 Main Street, Malden, MA 02148-5020, USA www.wiley.com/wiley-blackwell 